\title{
As (novas) tecnologias e o (velho) problema da determinação da responsabilidade penal nas equipas médicas
}

The (new) technologies and the (old) problem of the determination of criminal liability in medical teamwork

Las (nuevas) tecnologías y el (antiguo) problema de determinar la responsabilidad penal en equipos médicos

\section{Resumo}

Objetivo: discutir a determinação da responsabilidade penal dos profissionais de saúde que atuam em equipa, convocando o princípio da divisão do trabalho e o princípio da confiança. Metodologia: utilizou-se o método dedutivo, em que se avaliou a validade do princípio da confiança no âmbito da divisão do trabalho nas equipas de saúde, analisando a seu enquadramento dogmático no Direito Penal. Resultados: a doutrina penal divide-se quanto ao modo de determinação da responsabilidade por negligência, em caso de pluralidade de agentes, sobretudo no âmbito da divisão de trabalho vertical. Conclusão: a partir do princípio da divisão do trabalho e do princípio da confiança, é possível determinar a responsabilidade penal de cada membro de uma equipa de saúde quando da atuação negligente resultar uma ofensa à integridade física ou mesmo a morte do paciente.

Palavras-chave: Responsabilidade penal. Negligência. Equipe interdisciplinar de saúde.

\begin{abstract}
Objective: to discuss the determination of criminal liability of health professionals who work in teams, based on the principle of division of labor and the principle of trust. Methodology: the deductive method was used, in which the validity of the principle of trust in the scope of the division of labor in the health teams was evaluated, correlating it with the criminal aspects. Results: the penal doctrine is divided as to the way of determining liability for negligence in the case of plurality of agents, especially within the scope of the vertical division of labor. Conclusion: from the principle of division of labor and the principle of trust, it is possible to determine the criminal responsibility of each member of a health team when negligent performance results in an injury to the physical integrity or even the death of the patient.

Keywords: Criminal liability. Negligence. Interdisciplinary health team.
\end{abstract}

\footnotetext{
${ }^{1}$ Doutora em Direito pela Universidade de Coimbra, Portugal; professora auxiliar da Faculdade de Direito, Universidade de Coimbra, Portugal; investigadora do Instituto Jurídico, do Centro de Direito Biomédico e do Instituto de Direito Penal Económico e Europeu da Universidade de Coimbra, Portugal. E-mail: sfidalgo@fd.uc.pt

$2 \mathrm{O}$ texto que agora se publica corresponde à conferência apresentada no colóquio internacional Objetivos do Milénio, Direitos Humanos e Sociedade de Risco, que decorreu na Escola de Ciências Sociais da Universidade de Évora (Portugal), em 30 de maio de 2019. Na conferência, longe de aspirarmos a um tratamento profundo do tema, apontámos apenas alguns dos problemas relacionados com a determinação da responsabilidade penal nas equipas médicas. Nesta publicação, mantivemos o nosso propósito inicial, acrescentado apenas as referências bibliográficas estritamente necessárias. As indicações legislativas referem-se sempre a diplomas portugueses. Este estudo beneficiou de outro, realizado anteriormente, intitulado Responsabilidade penal no exercício da medicina em equipa: o princípio da confiança e o princípio da divisão do trabalho, publicado nos Estudos em Homenagem ao Prof. Doutor Jorge de Figueiredo Dias, Vol. II, Coimbra Editora, 2009, p. 417-435, com o qual coincide em certos aspetos.
} 


\section{Resumen}

Objetivo: este documento tiene como objetivo discutir la determinación de la responsabilidad penal de los profesionales de la salud que trabajan en equipo, con base en el principio de división del trabajo y el principio de confianza. Metodología: se utilizó el método deductivo, en el cual se evaluó la validez del principio de confianza en el alcance de la división del trabajo en los equipos de salud, analizando su marco dogmático en Derecho Penal. Resultados: la doctrina penal se divide en cuanto a la forma de determinar la responsabilidad por negligencia en el caso de la pluralidad de agentes, especialmente dentro del alcance de la división vertical del trabajo. Conclusión: desde el principio de división del trabajo y el principio de confianza, es posible determinar la responsabilidad penal de cada miembro de un equipo de salud cuando el desempeño negligente resulta en una lesión a la integridad física o incluso la muerte del paciente.

Palabras clave: Responsabilidad penal. Negligencia. Equipo interdisciplinario de salud.

\section{Introdução}

O progresso da ciência e da técnica provocou alterações profundas em todas as áreas do conhecimento. A medicina também tem vindo a beneficiar dessa evolução técnica e científica, sobretudo no que diz respeito aos exames complementares de diagnóstico e ao desenvolvimento de novos agentes terapêuticos. Nas instituições de saúde, equipamentos automatizados tornaram possível a realização de centenas de análises laboratoriais em apenas alguns minutos. Uma multiplicidade de métodos de imagem permite ao profissional de saúde ter uma representação visual do interior do organismo. É possível proceder-se à monitorização de alguns parâmetros vitais através de sensores e sistemas computorizados, que os projetam em gráficos, nos ecrãs (1). Técnicas cirúrgicas sofisticadas permitem que se faça intervenções até há uns anos inimagináveis.

Toda essa complexificação da atividade médica fez emergir um novo tipo de médico. A tendência é no sentido de uma divisão de competências. Os médicos reduzem cada vez mais o seu campo de atuação, aprofundando os seus conhecimentos num âmbito científico específico. E, seguindo a lógica da especialização médica, também a própria enfermagem se fragmentou e passou a ter áreas de cuidados especializados. As instituições de saúde apresentam-se hoje como organizações complexas onde a atividade médica é desenvolvida predominantemente no âmbito de equipas pluridisciplinares: as equipas de prestação de cuidados de saúde.

A atual complexificação da prática clínica, exigindo "capacidades de coordenação, de comunicação e de resposta perante o inesperado, que excedem a preparação das organizações", significa "naturalmente (...) maiores oportunidades de erro" (2, p. 157). Desse modo, no decurso de uma intervenção em que a intenção é melhorar o estado de saúde do 
paciente, ou até alcançar a sua cura, podem ocorrer erros de que derivem danos para o paciente ou mesmo a sua morte.

Perante a crescente especialização médica, a inevitabilidade da atuação interdependente de profissionais de diferentes especialidades sobre o mesmo doente, o reconhecimento de que as instituições de saúde são sistemas complexos e a aceitação de que há erros humanos que são inevitáveis, põe-se, com legitimidade, a questão de saber se haverá espaço para o Direito intervir em um ambiente tão denso, por vezes mesmo opaco, como é o das intervenções médico-cirúrgicas.

O Direito Penal reconhece a relevante função social exercida pela classe médica. $O$ Código Penal português (CP) dedica um tratamento diferenciado e privilegiado à atividade médica, através do regime específico das intervenções e tratamentos médico-cirúrgicos: nos termos do artigo 150. do CP, a intervenção médico-cirúrgica medicamente indicada, realizada por um médico, com finalidade terapêutica e segundo as leges artis não preenche o tipo de ofensa à integridade física (3, p. 68-69) (4, §§ 14 e 15) (5, p. 500-501). Verificados esses quatro pressupostos, a intervenção será atípica mesmo nos casos em que falhe nos seus objetivos, isto é, mesmo que agrave a lesão ou a doença ou provoque a morte do paciente (6, p. 450) (4, § 9).

No entanto, na atividade médica estão em causa bens que se contam entre os mais importantes da ordem legal dos bens jurídicos: a vida, a integridade física e a liberdade do paciente. Quando os profissionais de saúde atuam em violação do seu dever de cuidado, criando um risco não permitido que vem a concretizar-se numa ofensa ao corpo ou à saúde ou mesmo na morte do paciente, o Direito Penal não pode deixar de intervir: o profissional de saúde pode vir a ser punido por ofensa à integridade física por negligência (artigo 148. do CP) ou por homicídio por negligência (artigo $137 .{ }^{\circ}$ do CP) ${ }^{3}$.

Nesse sentido, este trabalho tem por objetivo discutir a determinação da responsabilidade penal dos profissionais de saúde que atuam em equipa, convocando o princípio da divisão do trabalho e o princípio da confiança.

\footnotetext{
${ }^{3}$ Em Portugal, não se distingue, nos factos culposos, entre negligência, imperícia ou imprudência. A designação dada ao facto culposo é facto negligente. Não será este o local adequado para nos alongarmos em considerações sobre a estrutura dogmática do facto negligente. Limitar-nos-emos a recordar que nele se manifestam um tipo de ilícito e um tipo de culpa específicos, diferentes dos que se verificam nos factos dolosos. O tipo de ilícito negligente consubstancia-se na violação, por parte do agente, de um dever objetivo de cuidado que sobre ele impende e que conduziu à produção de um resultado típico que seria previsível e evitável pelo homem médio pertencente ao círculo de vida do agente. O tipo de culpa negligente afirmar-se-á quando o agente exprimir no facto uma atitude interna de descuido ou leviandade perante o Direito e as suas normas (7, § 9, 35.ำ Cap., § 4, e 36. Cap., § 1).
} 
Para tanto, utilizou-se o método dedutivo, em que se avaliou a validade do princípio da confiança no âmbito da divisão do trabalho nas equipas de saúde, analisando a seu enquadramento dogmático no direito penal.

\section{Resultados e discussão: a delimitação dos deveres de cuidado na atuação em equipa}

Atuando os profissionais de saúde no âmbito de uma equipa, coloca-se o problema de saber de que modo há de determinar-se a responsabilidade de cada um se da intervenção médica resultar uma ofensa para o paciente. A determinação da responsabilidade de cada membro há de fazer-se a partir da delimitação dos deveres de cuidado. O princípio da divisão do trabalho e o princípio da confiança constituem os fundamentos com base nos quais a doutrina penal delimita os âmbitos de responsabilidade daqueles que desenvolvem a atividade no âmbito de uma equipa (7, 35. Cap., § 32) (8, p. 97 e ss.) (9, § 24, n. 25) (10, p. 217 e ss.) (11, p. 247 e ss.) (12, p. 115 e ss.). Será a partir desses princípios que há de determinar-se a responsabilidade dos diversos profissionais que, em conjunto, simultânea ou sucessivamente, intervêm no processo terapêutico do doente.

\section{O princípio da confiança}

Para que se possa imputar a um profissional de saúde um crime de ofensa à integridade física por negligência ou de homicídio por negligência, o agente tem de ter violado o dever de cuidado que sobre ele impendia e o resultado que se verificou - lesão do corpo ou da saúde, ou morte do doente - tem de ser imputado, precisamente, àquela violação do dever. Consequentemente, é necessário saber com exatidão quando se dá a violação do dever objetivo de cuidado. É preciso, assim, determinar quais as fontes concretizadoras do dever objetivo de cuidado no exercício da medicina $(13, \S 20)$ (8, p. 60 70).

Há, desde logo, que ter em consideração um conjunto de regras jurídicas de comportamento que regulam a atividade médica, como, por exemplo, no Estatuto da Ordem dos Médicos (Lei n. 117/2015, de 31 de agosto) e na legislação que regula a colheita e

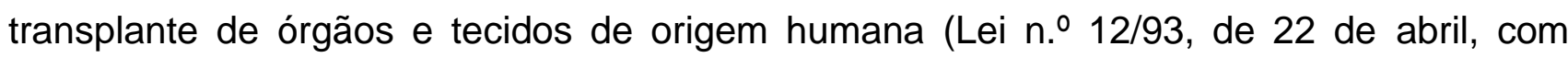
sucessivas alterações), a investigação clínica (Lei n.ำ 21/2014, de 16 de abril, com sucessivas alterações) e a procriação medicamente assistida (Lei n. 32/2006, de 26 de julho, com sucessivas alterações). 
Tendo conta, por um lado, a permanente evolução da medicina e, por outro, a multiplicidade e complexidade das diversas especialidades, seria impossível o legislador criar normas jurídicas concretizadoras do dever de cuidado em cada caso. Nos domínios como o da medicina, o dever objetivo de cuidado há de ser determinado atendendo também a um conjunto de regras fixadas pelo próprio círculo profissional - as leges artis medicinae. Entre nós, a expressão mais acabada dessa autorregulação dos profissionais de medicina é o Código Deontológico da Ordem dos Médicos (Regulamento n.ำ707/2016, de 21 de julho). Para além do Código Deontológico, há a considerar ainda, por exemplo, as declarações de princípios formuladas por organizações nacionais e internacionais de médicos, as guidelines resultantes de protocolos de atuação e de reuniões de consenso e os pareceres das comissões de ética.

Nem todas as leges artis medicinae assumem a forma de regras escritas - na sua grande parte, as regras da arte médica são regras não escritas. Frequentemente, para se concretizar o dever de cuidado no caso concreto é necessário, assim, fazer-se apelo aos costumes profissionais comuns ao profissional prudente. Por vezes - quando não é possível o recurso a normas jurídicas de comportamento, nem às leges artis (escritas ou não) - tem de recorrer-se à "figura-padrão" $\left(14, \S 6, n{ }^{\circ} 38\right)$, isto é, tem de usar-se como critério da violação do dever de cuidado "a não correspondência do comportamento àquele que, em idêntica situação, teria um homem [um médico] fiel aos valores protegidos, prudente e consciencioso" (7, 35. ${ }^{\circ}$ cap., $\S \S 19$ e 23$)$.

Todos esses elementos constituem fontes concretizadoras do dever objetivo de cuidado que impende sobre os médicos no exercício da sua atividade. Além das regras que regulam a atividade dos médicos, outras há que regulam a atividade dos farmacêuticos, dos enfermeiros e dos demais profissionais de saúde que intervêm nas diversas equipas de saúde.

Para a concretização do dever de cuidado no exercício da medicina em equipa, é necessário ter em consideração também o princípio da confiança. O princípio da confiança é visto hoje como um princípio de delimitação do tipo de ilícito negligente em caso de pluralidade de agentes (7, 35. cap., $\S \S 28$ e ss.) (15, p. 46 e ss., p. 79 e ss., p. 319 e ss.). O princípio da confiança é um princípio delimitador do dever objetivo de cuidado, isto é, quem atua ao abrigo do princípio da confiança não viola o dever de cuidado, logo, não preenche com a sua conduta o tipo de ilícito negligente. 
Segundo o princípio da confiança, na interação com terceiros, cada sujeito deve poder confiar que os demais se comportam de acordo com a norma de cuidado, "salvo se tiver razão concretamente fundada para pensar ou dever pensar de outro modo" (7, 35.ํ cap., § 28) (16, p. 466).

Tendo sido inicialmente afirmado pela jurisprudência e pela doutrina alemãs no âmbito do tráfego rodoviário, o princípio da confiança foi depois objeto de uma transposição para outras áreas, nomeadamente para o âmbito da divisão de trabalho nas equipas médicas. Assim, em matéria de divisão de tarefas, "qualquer membro (...) deve poder contar com uma atuação dos outros adequada à norma de cuidado (jurídica, profissional, estatutária, da experiência)" (7, 35. ${ }^{\circ}$ cap., § 32), quer a intervenção destes seja anterior, simultânea ou posterior ao comportamento que se analisa ${ }^{4}$.

\section{A divisão do trabalho e o âmbito de validade do princípio da confiança}

Numa equipa de prestação de cuidados de saúde, entre os diversos profissionais estabelece-se uma teia complexa de relações e o âmbito de atuação do princípio da confiança dependerá da posição que cada profissional assume na equipa.

Atendendo à tradicional distinção entre divisão do trabalho horizontal e vertical, a doutrina tem considerado que o âmbito de atuação do princípio da confiança não será o mesmo nos dois tipos de relações: o princípio da confiança terá, no âmbito das relações verticais, um campo de atuação mais restrito do que no âmbito das relações horizontais.

A divisão de trabalho horizontal é a que se verifica entre profissionais que, atendendo à sua formação e competência, se encontram em situação de igualdade e verificar-se-á em qualquer relação entre médicos de especialidades diferentes ou da mesma especialidade, desde que, nesse caso, nenhum dos médicos assuma funções de chefia. Pode ser estabelecida quer no caso de atuação simultânea, quer no caso de atuação sucessiva dos diversos profissionais sobre um paciente.

O caso típico de divisão de trabalho horizontal em medicina, tradicionalmente referido pela doutrina, é o da relação que se estabelece entre cirurgião e anestesiologista (19, p. 572) (10, p. 230 e ss.) (12, p. 136 e ss.). Esses profissionais exercem conjuntamente funções

\footnotetext{
${ }^{4}$ Jakobs esclarece que a conduta danosa pode ser anterior ao comportamento que se analisa. É o que acontece, por exemplo, quando o cirurgião utiliza um bisturi confiando que ele foi previamente esterilizado não tendo, na realidade, tal instrumento sido objeto de esterilização (17, p. 219). Teresa Pizarro Beleza também refere o princípio da confiança no caso de esterilização de objetos cirúrgicos (18, p. 517-518).
} 
complementares, desenvolvendo cada um a sua atividade de acordo com os conhecimentos próprios das respetivas especialidades.

Por ser uma relação não hierárquica entre o cirurgião e o anestesiologista, o princípio da confiança atuará na sua plenitude. Cada especialista, por regra, pode confiar na correta realização de funções por parte do outro - nenhum deles controla a atividade do outro -, não sendo qualquer um dos especialistas responsável pelos atos realizados pelo colega. Cada um dos especialistas será apenas responsável por controlar os perigos que, no seu específico âmbito de competência, ameacem concretizar-se numa ofensa para o doente.

A divisão de trabalho vertical verifica-se quando há uma relação de hierarquia em que uma pessoa recebe instruções e é controlada por outra que se encontra num nível superior, estabelecendo-se entre ambas uma relação de supra/infra ordenação. O exemplo tradicionalmente indicado desse tipo de divisão de trabalho é o que se verifica na relação entre o médico cirurgião (chefe de equipa) e os enfermeiros que com ele colaboram na cirurgia. No entanto, a divisão de trabalho vertical não se resume à relação entre médicos e profissionais de saúde não médicos. Pode verificar-se também uma relação de trabalho vertical entre médicos da mesma especialidade em que um deles se encontra numa situação de superioridade em relação ao outro, por assumir funções de chefia de uma equipa médica, como por exemplo, o cirurgião chefe de equipa em relação aos cirurgiões ajudantes (20, p. 184) (21, p. 54).

Tradicionalmente, entendia-se que no âmbito das relações hierárquicas o chefe de equipa assumia globalmente a realização do processo terapêutico, pelo que cada ato dos subordinados não seria senão uma parcela delegada da atividade assumida por aquele (22, p. 433). Sobre o chefe de equipa recairia um conjunto de deveres que compreenderiam, desde logo, o dever de seleção dos seus colaboradores e de comprovação da sua qualificação técnica e pessoal, mas também os deveres de informação, instrução e de vigilância constante da sua atuação, de modo a evitar eventuais erros $\left(23, \S 1, \mathrm{n} .{ }^{\circ} 174\right)$. Tal dever de controlo constante da atividade dos subordinados inexistiria apenas em situações em que o chefe de equipa tivesse motivos fundados para confiar na atividade dos seus colaboradores. Afirmava-se, assim, como regra, o princípio da não confiança (24, p. 155156).

No entanto, essa posição tem sido alvo de fundadas críticas por parte da doutrina maioritária, ao defender que, também no âmbito das relações hierárquicas, há de ser 
convocado o princípio da confiança, ainda que com um campo de atuação mais limitado do que nas relações não hierárquicas $(20$, p. 186-187) (25, p. 50-51) $(23, \S 1$, n.os 175 e ss. e 181 e ss.) (26, p. 1056) (27, p. 225 e ss.) (12, p. 147 e ss.). Em rigor, também no âmbito das relações verticais, só terá sentido afirmar o princípio da divisão do trabalho se cada um dos participantes puder confiar numa atuação dos demais de acordo com as regras.

De qualquer modo, no âmbito da divisão do trabalho vertical, independentemente das competências próprias do pessoal subordinado, a relação de superioridade hierárquica determina o surgimento, para o superior, de deveres de organização e coordenação da atuação da equipa.

O superior tem o dever de proceder à distribuição de tarefas de modo a que todas as tarefas sejam corretamente atribuídas - o superior deverá escolher, para desempenhar as diversas tarefas, profissionais que estejam em condições de o fazer de modo adequado. No que diz respeito ao dever de organização e coordenação da atividade da equipa, vale o princípio da confiança: quando não concorrerem circunstâncias que alterem a normal presunção de capacidade que é lícito supor nos colaboradores, o superior pode confiar na qualificação deles, bem como na atuação de acordo com o dever de cuidado que sobre eles impende (22, p. 435-436).

Além do dever de organização e coordenação inicial, sobre o superior impenderão também, em certas situações, deveres de vigilância, instrução e coordenação no decurso da atividade da equipa. Ou seja, sobre o superior impenderá, em certas circunstâncias, um dever de controlo da atuação dos seus subordinados. A atuação médica é uma atividade perigosa e no decurso da intervenção podem surgir falhas de qualificação, de comunicação e de coordenação (28, p. 393 e ss.) (12, p. 161 e ss.). O dever de controlo que impende sobre o chefe de equipa destina-se a evitar que os perigos se concretizem em ofensas à vida ou à integridade física dos doentes.

Há consenso na doutrina quanto à afirmação de um dever de controlo a cargo do chefe de equipa, para fazer face às especiais fontes de perigo que possam manifestar-se. Porém, quanto à extensão desse dever, as opiniões divergem.

A extensão do princípio da confiança no âmbito das relações hierárquicas depende do alcance que se conceder ao dever de controlo da atuação dos subordinados. O princípio da confiança e o dever de controlo delimitam-se reciprocamente: quanto maior for o alcance do dever de controlo, menor será a extensão do princípio da confiança e, inversamente, 
quanto menor for o alcance do dever de controlo, maior será a extensão do princípio da confiança.

Na doutrina alemã, Umbreit alarga de tal modo os deveres de controlo do superior sobre a atuação dos subordinados que acaba por negar a vigência do princípio da confiança com carácter geral nas relações verticais (29, p. 118 e ss., p. 150 e ss. e p. 172 e ss.).

Também na doutrina italiana há quem defenda que não pode convocar-se o princípio da confiança no âmbito das relações hierárquicas, pois tal seria incompatível com o dever de controlo que impende sobre o superior (30, p. 173) (31, p. 756).

Entendemos, no entanto, que o princípio da confiança também tem validade geral nas relações verticais. O chefe de equipa não atuará contra o seu dever de cuidado quando confiar que os seus colaboradores cumprirão adequadamente as tarefas para as quais se encontram oficialmente habilitados. Quando não houver motivos para duvidar da preparação e da capacidade dos colaboradores, valerá plenamente o princípio da confiança (25, p. 51). Com a afirmação de um dever de vigilância permanente da atividade dos colaboradores correr-se-ia o risco de esvaziar de conteúdo a distribuição de tarefas. Não tem sentido impor ao superior que supervisione a atuação dos seus colaboradores, (mesmo que se trate de colaboradores com formação não médica, quando realizam tarefas que são, precisamente, da sua competência e especialidade.

O dever de controlo da atividade dos colaboradores surgirá na esfera do chefe de equipa apenas como um dever de cuidado secundário que, segundo Stratenwerth, surge somente no caso em que "a expectativa de um comportamento de acordo com o dever, tendo em conta a situação ou a pessoa do outro, se torne debilitada" (28, p. 392) ${ }^{5}$. O chefe de equipa pode confiar na atuação adequada dos seus subordinados, salvo se circunstâncias especiais do caso concreto o fizerem (ou deverem fazer) duvidar da capacidade daqueles para desempenhar as tarefas em causa e, consequentemente, o fizerem (ou deverem fazer) esperar uma conduta incorreta por parte deles. Tal acontecerá, designadamente, nas situações em que o superior se aperceber (ou dever aperceber) de erros do colaborador 6 . Também nos casos em que um membro da equipa, apesar de ter qualificação suficiente, for

\footnotetext{
${ }^{5}$ Nas palavras de Stratenwerth, os deveres de controlo "não devem ser deduzidos de forma geral a partir da previsibilidade dos erros dos outros nem da mera possibilidade de intervir. Portanto, o princípio da confiança limita, por sua vez, quando não existem circunstâncias especiais, também os deveres de controlo. Caso contrário seria impossível (...) uma efetiva divisão do trabalho" (32, § 15, n.․ 66, grifo dos autores).

${ }^{6}$ Marco Mantovani esclarece que, para excluir o princípio da confiança, não é suficiente um erro que, apesar de cognoscível, seja insignificante, mas apenas o erro que constituir uma fonte de perigo para o paciente (33, p. 1198-1199).
} 
ainda inexperiente no desempenho da tarefa em causa ${ }^{7}$, além do dever prévio de informação e instrução no início da intervenção, sobre o superior recairá ainda um dever de vigilância da atividade do colaborador inexperiente. Pode suceder também que um colaborador experiente e habitualmente competente não tenha cometido qualquer erro, mas, no decurso da intervenção, manifeste não se encontrar em plenas condições físicas e/ou psíquicas, nomeadamente por se encontrar cansado por excesso de trabalho (21, p. 68). Também nesse caso o princípio da confiança deverá ceder o seu lugar a um dever (secundário) de controlo por parte do superior sobre a atuação do colaborador.

Excluídas, porém, essas situações excecionais, o chefe de equipa poderá confiar na atuação dos seus colaboradores (8, p. 149 e ss.).

\section{Conclusão}

O exercício da medicina em equipa foi uma das respostas dadas pelo corpo médico à complexificação da atividade médica. Os princípios da divisão de trabalho e da confiança são uma construção dogmática de que nos socorremos para a determinação da eventual responsabilidade penal dos profissionais de saúde envolvidos no exercício da medicina em equipa. A convocação do princípio da confiança como princípio delimitador dos deveres de cuidado nas relações que se estabelecem entre os vários profissionais de saúde apresentase hoje como um caminho a seguir para fazer face ao aumento dos riscos associado à agressividade e à complexidade da medicina. Se sobre o chefe de equipa impender um dever de controlo constante em relação aos demais membros da equipa, aquele profissional não poderá dedicar-se com a atenção necessária às tarefas médicas que especificamente Ihe competem. Afirmando-se o princípio da confiança com validade geral, quer nas relações horizontais, quer nas relações verticais, permite-se a cada profissional concentrar-se nas tarefas que Ihe são concretamente atribuídas. Desse modo, delimita-se o âmbito de responsabilidade de cada elemento da equipa e torna-se claro que a segurança do doente é responsabilidade de todos.

São inegáveis as conquistas que o desenvolvimento da ciência e da técnica em medicina permitiu alcançar. $O$ recurso sistemático a novos meios tecnológicos não pode, porém, substituir toda a riqueza que se constrói através do diálogo atento e do contacto direto do médico com o doente (1). A afirmação do princípio da confiança não pode,

\footnotetext{
${ }^{7}$ Refira-se que o princípio da confiança não poderá ser convocado em relação a membros da equipa que se encontrem ainda em formação (34, p. 975 e ss.).
} 
naturalmente, eliminar o diálogo profícuo entre os diversos profissionais que intervêm no processo terapêutico do doente. $\mathrm{Na}$ sociedade do risco, a medicina deverá continuar a beneficiar do progresso da ciência e da técnica, mas não poderá esquecer a dimensão humana que sempre a caracterizou (1).

\section{Referências}

1. Lemos C. A Medicina na Era de Técnica. Observador. 22 ag 2018. Disponível em https://observador.pt/opiniao/a-medicina-na-era-da-tecnica [Acesso em 27.maio.2019].

2. Oliveira GF. Recensão de: José Fragata e Luís Martins. O erro em Medicina. Perspetivas do indivíduo, da organização e da sociedade. Coimbra, Almedina, 2004, Lex Medicinae Revista Portuguesa de Direito da Saúde, 3, 2005: 157-168.

3. Dias JF, Monteiro JS. Responsabilidade médica em Portugal. Boletim do Ministério da Justiça. 332, 1984: 21-79.

4. Andrade MC. Comentário ao artigo 150 do Código Penal. In: Comentário Conimbricense do Código Penal, Parte Especial. Tomo I. 2. ㄹ ed. Coimbra: Coimbra Editora; 2012.

5. Brito TQ. Os crimes contra a integridade física. In: Direito Penal - Parte Especial: lições, estudos e casos. Coimbra: Coimbra Editora; 2007.

6. Andrade MC. Consentimento e Acordo em Direito Penal (Contributo para a Fundamentação de um Paradigma Dualista). Coimbra: Coimbra Editora; 2004.

7. Dias JF. Direito Penal. Parte Geral. 3aㅡ ed. Coimbra: Gestlegal; 2019.

8. Fidalgo S. Responsabilidade penal por negligência no exercício da medicina em equipa. Coimbra: Coimbra Editora; 2008.

9. Roxin C. Strafrecht. Allgemainer Teil. Band I. Grundlagen. Aufbau der Verbrechenslehre. 4. Auf. München: Verlag C. H. Beck; 2006.

10. Marinucci G, Marrubini G. Profili penalistici del lavoro medico-chirurgico in équipe. Temi, 1968: 217-234.

11. Romeo Casabona CM. El médico y el derecho penal, I. La actividad curativa (Licitud y responsabilidad penal). Barcelona: Bosch, Casa Editorial, S.A.; 1981.

12. Jorge Barreiro A. La imprudencia punible en la actividad médico-quirúrgica. Madrid: Editorial Tecnos, 1995.

13. Faria PR. Comentário ao artigo 148 do Código Penal. In: Comentário Conimbricense do Código Penal, Parte Especial. Tomo I. 2. ${ }^{a}$ ed. Coimbra: Coimbra Editora; 2012. 
14. Burgstaller M. Kommentierung zu § 6 StGB. In: Wiener Kommentar zum Strafgesetzbuch, 2. Auf. Wien: Manzsche Verlags - und Universitätsbuchhandlung; 2001.

15. Fidalgo S. Princípio da Confiança e Crimes Negligentes. Coimbra: Almedina; 2018.

16. Costa JF. O perigo em direito penal (contributo para a sua fundamentação e compreensão dogmáticas). Coimbra: Coimbra Editora; 2000.

17. Jakobs G. Imputación objetiva, especialmente en el ámbito de las instituciones jurídicopenales del "riesgo permitido", la "prohibición de regreso" y el "principio de confianza". In: Estudios de Derecho Penal, Madrid: Editorial Civitas, S.A.; 1997: 209-222

18. Beleza TP. Direito Penal. 2.ํvol. Lisboa: AAFDL; 2010.

19. Carstensen G. Arbeitsteilung und Verantwortung aus der Sicht der Chirurgie. Langenbecks Archiv für Chirurgie, 335, 1981: 571-573.

20. Wilhelm D. Strafrechtliche Fahrlässigkeit bei Arbeitsteilung in der Medizin, Jura, 4, 1985: 183-188.

21. Feijó Sánchez B. El principio de confianza como criterio normativo de imputación en el derecho penal: fundamento y consecuencias dogmáticas, Derecho Penal y Criminología, 69, 2000: 37-76.

22. Gómez Rivero MC. La responsabilidad penal del médico. $2^{\underline{a}}$ ed. Valencia: Tirant lo Blanch; 2008.

23. Ulsenheimer K. Arztstrafrecht in der praxis. 3. Auf. Heidelberg: C. F. Müller Verlag; 2003.

24. Crespi A. La responsabilità penale nel trattamento medico-chirurgico con esito infausto. Palermo: G. Priulla Editore; 1955.

25. Wilhelm D. Probleme der medizinischen Arbeitsteilung aus strafrechtlicher Sicht. Medizinrecht, 2, 1983: 45-51.

26. Mantovani M. Alcune puntualizzazioni sul principio di affidamento, Rivista Italiana di Diritto e Procedura Penale, 1997: 1051-1060.

27. Landro AR. Vecchie e nuove linee ricostruttive in tema di responsabilità penale nel lavoro medico d'équipe, Rivista Trimestrale di Diritto Penale dell'Economia, 1-2, 2005: 225-272.

28. Stratenwerth G. Arbeitsteilung und ärztliche Sorgfaltsplicht. In: Festschrift für Eb. Schmidt. Göttigen: Vandenhoeck und Ruprecht; 1961: 383-400.

29. Umbreit HW. Die Verantwortlichkeit des Arztes für fahlässiges. Verhalten anderer Medizinalpersonen. Frankfurt am Main: Peter Lang, 1992. 
30. Ambrosetti F, Piccinelli M, Piccinelli R. La responsabilità nel lavoro medico d'équipe. Profili penali e civili. Torino: Utet, 2003.

31. Bilancetti M. La responsabilità penale e civile del medico. 5.ㄹ ed. Milano: CEDAM; 2003.

32. Stratenwerth G, Kuhlen L. Strafrecht. Allgemeiner Teil I. Die Straftat. 6. Auf. München: Verlag Franz Vahlen; 2011.

33. Mantovani M. Sui limiti del principio di affidamento. L'Indice Penale. 1999: 1195-1204.

34. Fidalgo S. Responsabilidade penal do médico interno e do orientador de formação, in: Direito penal. Fundamentos dogmáticos e político-criminais. Homenagem ao Prof. Peter Hünerfeld. Coimbra: Coimbra Editora, 2013: 975-994. 